\title{
Sócrates y la prehistoria de las autobiografías
}

\author{
Héctor Zagal \\ Facultad de Filosofía \\ Universidad Panamericana \\ hzagal@up.edu.mx
}

Anduve buscándome a mí mismo.

Heráclito, Fragmento 101.

\section{La biografía usurpada}

La historia oficial de la filosofía da un vuelco con la aparición de Sócrates. Los manuales enseñan que los primeros sabios - Tales, Anaxímenes, Empédocles, Heráclito... - se interesaron fundamentalmente por la naturaleza. El arjé de la physis, y no el ser humano, captó la atención de los filósofos antiguos. Si exceptuamos a Jenófanes de Colofón, cuyas agudas consideraciones sobre el antropomorfismo religioso sorprenden incluso en nuestro tiempo, los presocráticos no se pasmaron ante la condición humana y sí en cambio ante los ciclos del mundo físico. Esta despreocupación desconcierta, si consideramos que para aquellas épocas los cantos homéricos y las tragedias se habían asomado en los abismos de la conciencia.

Los héroes homéricos no se conforman con moverse como piezas en el tablero de ajedrez de los dioses olímpicos. Esas mujeres y esos hombres se saben agentes, si no completamente libres, sí plenamente capaces de ejecutar bellas acciones, de obrar hazañas y ruindades, se saben, en suma, «pequeños cosmos»: universos en miniatura, donde se dan cita las pasiones, las virtudes y lo vicios, la razón y los sentimientos. Odiseo y Héctor saben que están haciendo historia, saben que su vida será narrada y que, más allá de sus derrotas o triunfos en el campo de batalla, los rapsodas cantarán su gloria inmortal. Los héroes, muy en especial los homéricos, ac- 
túan para la posteridad, actúan con un impresionante sentido del pasado y del futuro. Antes de entrar en combate, los guerreros se presentan a sí mismos, hablan de su estirpe, su lugar de origen, sus hazañas. Saben de dónde provienen y, a su manera, saben hacia dónde se dirigen. Los héroes cuentan su historia; precisamente en eso se distinguen del pueblo llano, en que ellos traen a cuestas una narración salpicada de acciones bellas.

Ulises escucha su propia historia en un banquete (una de las primeras auto referencias de la literatura) y llora mientras el aedo canta sus desventuras.

[...] el aedo, movido del dios, modulaba su canto desde el punto en que aquellos argivos, de después de dar fuego a las tiendas, se hicieron al mar en las sólidas naves.

Del caballo en la entraña escondido, los otros en torno se agrupaban de Ulises ya en medio de Troya; los teucros por sí mismos lo habían arrastrado al alcázar y, erguido en mitad, discutían a su pie y en confuso alboroto.

$[\ldots]$

Y contaba después el saqueo que aquéllos [los argivos] hicieron. Tras fluir del caballo dejando su hueca emboscada: cada cual por un lado pillaba el alcázar excelso, pero Ulises, dijérase Ares, marchó hacia las casas de Deífobo; al lado llevaba al sin par Menelao.

Allí - dijo - empeñó su más duro combate, más pronto la victoria inclinó a su favor la magnánima Atenea. Tales hechos contaba aquel ínclito aedo y Ulises consumíase dejando ir el llanto por ambas mejillas. [...]

No hubo nadie en verdad que notara sus lloros; Alcónoo solamente, al hallarse más cerca, lo estaba observando; diose cuenta de todo al oír sus profundos suspiros ${ }^{1}$.

El héroe se encuentra en una tesitura extraña: un tercero le narra su propia vida. Si en todo momento Ulises es consciente de que sus

1 Odisea, canto VII, 499-534. Usamos la traducción de José Manuel Pabón, Madrid: Gredos 2001 . 
desventuras obedecen al capricho de los dioses y que su historia se forja al golpe del cincel de voluntades ajenas; el canto VIII lo coloca en una circunstancia desconcertante. Su vida ya no le pertenece; su biografía está en manos de los cantores. Ulises aún no ha muerto y ese patrimonio - la propia biografía - le ha sido expropiado. Odiseo se ha perdido a sí mismo, quienes cantan y escuchan las cuitas del guerrero le compadecen en las estrofas, pero son incapaces de consolarle en el presente. Lo tienen ahí, a sus pies y, sin embargo, nadie le reconoce. Lloran por el Ulises abstracto pero no consuelan al de carne y hueso. Estamos ante la primera conciencia «alienada», por decirlo al modo de Hegel. Los cantos homéricos usurpan la biografía de Ulises. Parte de la tragedia del héroe radica precisamente en las dificultades para darse a conocer, no puede revelarse abiertamente como quien es - el rey de Ítaca, hijo de Laertes, esposo de Penélope - y más de alguna ocasión se ha de esconder bajo el disfraz de mendigo o simple náufrago.

En realidad esta expropiación de la propia historia se atisba ya en la Ilíada desde el momento en que los actores se saben personajes, individuos con la obligación de recitar un parlamento, con el deber de estar a la altura de las circunstancias. Héctor, Aquiles, Patroclo se deben a la posteridad para que se canten sus bellas acciones. La dramática despedida de Héctor de su familia se construye a partir del fatum; el troyano prevé su muerte y la afronta como el actor que piensa «que suceda lo que suceda, el espectáculo ha de continuar». El rapsoda dibuja a los guerreros con un enorme peso a cuestas: dar ejemplo, mostrar la excelencia, areté, a los jóvenes de la Grecia clásica. Los héroes griegos se deben, pues, a la posteridad. El futuro, la historia, el qué dirán: he ahí la clave.

Biografías usurpadas: los héroes no viven para sí mismos sino para edificar, para amasar un capital de hazañas que constituye su pase de entrada a la gloria inmortal. El precio de la inmortalidad se finca en la fama: depende de nuestros narradores y espectadores.

¿Por qué no escriben su vida los héroes? Además de que más de alguno no sabría leer ni escribir, la inmortalidad no radica en el texto, sino en el recuerdo. Lo importante para Héctor y para Ulises no es que Homero - si en verdad existió- ponga por escrito sus afanes y luchas, sino que se les recuerde. No olvidemos que la 
Ilíada y la Odisea son, antes que nada, cantos. En ambos casos se invoca a la divinidad muy al inicio: «Canta, joh diosa!, la cólera del Pélida Aquiles»; «Musa, dime del hábil varón que en su largo extravío, tras haber arrasado el alcázar sagrado de Troya, conoció las ciudades y genio de innúmeras gentes». La divinidad custodia el canto. Ella inspira a los aedos, guardianes de la gloria inmortal, y no los libros que se guardan en los arcones. Aspirar a pervivir en el recuerdo de los demás, nos condena a vivir del honor. $\mathrm{Y}$ el honor es algo que depende, ciertamente, de nuestras acciones, pero, sobre todo, depende de quienes nos lo tributan. Biografías usurpadas, porque quien rinde los honores ejerce el derecho de autoría sobre los héroes.

La odisea del desdoblamiento del yo

Resulta desconcertante, pues, que los filósofos presocráticos - capaces de elaborar teorías refinadas sobre el origen de la vida - no se percataran del juego de espejos de la Odisea. Resulta desconcertante que, teniendo ante los ojos el caso de un Yo desgarrado por el expolio de su propia historia, no navegasen en los mares interiores y nebulosos de la conciencia.

Ulises llora doblemente: por sufrir las penas de su viaje trunco, por escuchar la magnitud de su tragedia. El héroe conoce la magnitud de su desgracia después de oír en labios de otro sus propios males. Resultan curiosos los vericuetos por donde la autobiografía viene a darse en la literatura homérica. La auto-presentación cede el paso al espejo. Los cantos homéricos no parecen confiar demasiado en la capacidad del ser humano para penetrar su propio yo. Este recelo es propio de cualquier cultura del honor. La reputación se construye sobre la base de la opinión ajena; los otros son el espejo dónde uno conoce la hondura y calidad de las propias acciones.

Algo análogo sugerimos en la tragedia. Los coros trágicos funcionan frecuentemente como una especie de espejo para que el héroe se reconozca a sí mismo. El coro tiene la función, en otras, de hacerlo caer en la cuenta de sus miserias y desaciertos. El coro suele conducir al personaje al reconocimiento de la hybris que ha come- 
tido. Sin sus estrofas, el Yo quedaría lejos de conocerse y de narrar su propia historia. Edipo es emblemático. El héroe trágico se desconoce a sí mismo y no calibra las consecuencias de sus actos. La trama de la obra consiste, valga el juego de palabras, en desenredar la madeja de un Yo enmarañado en circunstancias que parecen resultarle ajenas pero que, a la hora de la verdad, lo componen en un sentido mucho más profundo del que el personaje piensa. Edipo no quiere matar a su padre y, sin embargo, le arranca la vida. No quiere acercarse incestuosamente a su madre, pero se ayunta con ella. Todo porque desconoce sus raíces, camufladas por los trucos del destino. En verdad Edipo no sabe quién es él, sino hasta su muerte, cuando es acogido en Colono.

Los trágicos, al igual que los poetas homéricos, recelan de las capacidades introspectivas del ser humano. El destino es demasiado poderoso, nos impide fabricar una imagen cabal de nosotros; la formación de nuestra identidad requiere, por tanto, de la ayuda de otros. Ciertamente, en los trágicos la cuestión del honor ha pasado a un segundo plano. Lo más relevante no es el modo como las generaciones posteriores recordarán a Edipo; lo crucial para él es conocerse a sí mismo. Sólo el autoconocimiento verdadero salva de las trampas del destino. La salvación proviene de la verdad, no de la memoria de la humanidad. Por extraño que suene, Edipo es más libre que Aquiles y que Odiseo. El rey de Tebas no es esclavo del qué dirán. Lucha en contra de una fuerza impersonal que le impide ser feliz, pero a lo largo de las tragedias Edipo profundiza en el conocimiento del su Yo y en esa medida se libera; los héroes homéricos, en cambio, terminan por perder su historia. Odiseo presencia la enajenación de su biografía en manos de los aedos; Edipo se apropia de su vida en la medida en que auxiliado por el coro descubre su estirpe.

Ahora bien, en los trágicos aparece con todas sus letras el eterno problema de cualquier relato autobiográfico: nadie se conoce cabalmente a sí mismo. Hay algo que se oculta a la luz de nuestra inteligencia. Si nos hubiésemos topado con Edipo antes de llegar a Tebas, y, a la usanza de la Ilíada, le hubiésemos preguntado por su progenie, el infeliz nos habría contado una historia falsa: la que él conocía. El engaño sobre la propia vida marca la condición huma- 
na. ¡Qué falsa versión de su vida nos hubiese contado Edipo de no mediar la tragedia! El desdoblamiento y la apariencia se instalan de lleno en las conciencias trágicas.

\section{Sócrates, el escultor}

El giro antropológico de Sócrates no debe sorprendernos. No podía ser de otra manera después de los ríos de conciencia que fluyen en Esquilo, Sófocles y Eurípides. Los poetas épicos y trágicos ya se habían sumergido profundamente en el Yo, como para que los filósofos siguiesen rehusando zambullirse en los caudales interiores. Mientras Tales especulaba si el agua era el principio del universo y Parménides afirmaba el carácter absoluto del Ser, la literatura griega se afanaba por revelar los secretos de la conciencia. Qué extraño resulta, entonces, que entendimientos tan dotados (como los de Heráclito, Anaxímenes o Empédocles) no se hubiesen abocado al problema de la identidad personal. Qué extraño resulta que la filosofía caminase por el sendero de la física, mientras que el arte, lo mismo la literatura que la escultura, se esmeraba por forjarse una imagen del modo como se construye y describe la identidad personal.

Sócrates da el golpe de timón cuando proclama como guía de su filosofía el «Conócete a ti mismo». Esta máxima no le viene de la filosofía, una filosofía absorta en el problema del cambio, sino de uno de los santuarios más importantes de Grecia. La frase estaba inscrita en el tempo de Apolo en Delfos y de ahí la tomó el ateniense. Apolo, un dios asociado a la cítara, a la armonía y la mesura, recomienda el conocimiento propio como una vía para evadir la traicionera hybris.

Sócrates asumió el reto planteado por la epopeya y la tragedia. La filosofía socrática - al menos tal y como nos las trasmitió Platón en sus diálogos de juventud - consiste en un paulatino proceso de desnudamiento del alma hasta dar con lo que realmente es. Este proceso se había iniciado en la escultura. La desnudez no era para las artes plásticas helénicas un punto de partida, sino un punto de llegada. A lo largo de los siglos, los escultores despojaron pri- 
mero al varón, y después a la mujer, de todo aquello que ocultaba su cuerpo. La belleza, intuyeron, radica en la presencia del cuerpo desprovisto de vestidos y adornos, es el cuerpo desnudo, dónde se manifiesta lo que cada persona es en verdad. Los kyrieu arcaicos son retratos personales, no tanto porque capturen rostros singulares, sino porque representan cuerpos irrepetibles, cuerpos labrados con horas de palestra. Los escultores griegos renunciaron a caracterizar a los jóvenes atletas a través de sus indumentarias; lo que los caracteriza, precisamente, es la falta de ella, como si los artistas quisiesen demostrarnos que la identidad no radica en lo externo, sino en el cuerpo recio, que revela el esfuerzo de los atletas en el gimnasio.

Sócrates fue hijo de una partera, y el filósofo se preció de haber heredado la profesión de la madre. La mayéutica, gustaba repetir, es el arte de ayudar a parir ideas. Pero Sócrates también tuvo por padre al escultor Sofronisco, y este hecho suele pasar inadvertido. Seguramente en el taller de su padre entendió que el descubrimiento de la identidad personal radica en des-cubrir, en retirar los velos que ocultan el cuerpo. La investigación del Yo no consiste tanto en escribir sobre uno, cuanto en descubrir, en despejar el alma de todo el follaje que esconde su núcleo. El escultor quita del mármol lo sobrante y da con el cuerpo desnudo y simple.

Análogamente, para dar con lo que uno es, hace falta desnudar al alma de todos aquellos artificios que la cubren. Recordemos el pasaje del Cármides, donde Sócrates, antes de regocijarse contemplando el cuerpo del joven recién llegado del servicio militar a su natal Atenas, conmina a su compañero a desnudar primero el alma del muchacho y regocijarse en esa belleza.

\section{Ironía y terapia}

El Sócrates de los primeros diálogos platónicos se preocupa por ayudar a sus amigos a parir ideas; esta tarea también puede entenderse como esculpir almas. Su pretensión es la de encontrar el Yo auténtico: cumplir la máxima délfica. Tal intención supone una premisa importantísima para la historia de las autobiografías. Para 
Sócrates, y especialmente para Platón, existe una escisión entre el Yo aparente y el Yo real. En ocasiones la belleza moral y física de un Yo no es sino una mera ilusión, un fantasma, una fantasía (phantasía viene de phanerós, «lo visible»). La dualidad mundo físico/mundo de las ideas tiene un correlato en la subjetividad: Yo aparente/ Yo real.

Esta idea se expresa contundentemente en el Gorgias, diálogo que suele subtitularse como De la retórica, y dónde Platón habla por boca del Sócrates, a diferencia de los primeros diálogos, comúnmente catalogados como diálogos históricos.

Sócrates se encuentra con Gorgias, Polo y Calicles. El primero se ufana de sus habilidades retóricas, un hombre diestro en los juegos de ideas, pero también en la lid política, un individuo seguro de sí mismo. La discusión se sucede atropelladamente; Sócrates desprecia profundamente esas pretensiones y el diálogo desemboca en un callejón sin salida.

No obstante, se da pie a que Platón esboce una interesante teoría sobre la terapia (del griego, therapeía: «cuidado», «cura»). Existe una terapia del cuerpo: la gimnástica y la medicina; también existe una pseudo-terapia del cuerpo, la cosmética y la gastronomía. La primera se preocupa verdaderamente por la salud del cuerpo, aún cuando para ello haya que someterlo a privaciones. La segunda se afana en adularlo, no le exige esfuerzos, se contenta con darle dulces y perfumes que sólo aparentemente son saludables. La pseudoterapia maquilla el cuerpo, ni lo cuida, ni lo sana:

La adulación gastronómica lleva la máscara de la medicina; de este mismo modo, la cosmética lleva la máscara de la gimnasia; nociva, engañosa, innoble y servil, engaña mediante formas, colores, lisura, y ropa, de manera tal que hace que los hombres atraigan la belleza ajena y descuiden la propia, que proviene de la gimnasia ${ }^{2}$.

De manera acontece con el alma. La justicia y las leyes cuidan del alma, pues ellas procuran su belleza. La retórica y la sofística, por el contrario, sólo en apariencia embellecen el alma. El retórico 
y el sofista dan la impresión de ser sabios y justos, pero en realidad no lo son; debajo de toda su palabrería y sus deslumbrantes raciocinios, no hay nada sino ignorancia e injusticia. Hacia el final del Gorgias, Sócrates expresa su convencimiento de que la auténtica terapia limpia el alma y la prepara para la isla de los bienaventurados, mientras que aquellas que han sido objetos de los pseudo-cuidados de los charlatanes irán a dar al Hades.

La referencia al más allá no es, en manera alguna, pura anécdota. Sólo refiriéndonos a un horizonte de futuro podemos calibrar el estado de salud de la propia existencia. En otro contexto, con palabras muy rudas, Sócrates reprocha al sofista Calicles su falta de preparación para la muerte:

En cuanto a mí, Calicles, he sido convencido por estos relatos, e indago cómo puedo aparecer ante el juez con el alma lo más sana posible; dejo los honores a la mayoría de los hombres y, persiguiendo la verdad, trato realmente - hasta donde sea capaz - de vivir como el mejor y, cuando muera, de morir así. Pero también exhorto a ello a todos los demás hombres, en la medida de lo posible. Además, te exhorto también a ti para que vivas esta vida y para que libres esta lucha, de la cual yo afirmo que es una lucha contraria a todas las luchas de aquí. Y te vitupero, porque no serás capaz de ayudarte a ti mismo cuando te toque el proceso y el juicio, del cual acabo de hablar, sino que - cuando llegues con aquel juez, el hijo de Egina, y cuando aquél, habiéndote recibido, te lleve consigo - tú estarás allá con la boca abierta y sentirás vértigo, no menos que yo aquí, y tal vez alguien te pegará en la cara sin honor y te calumniara de todas maneras ${ }^{3}$.

En Platón, la sofística es el enemigo del verdadero conocimiento del yo. Si el precepto délfico rezaba: «Conócete a ti mismo», los sofistas, opinan Sócrates y su discípulo, son los principales enemigos del viaje por la interioridad. El sofista carece de sabiduría porque ha renunciado a explorar su yo; fascinados por sus habilidades argumentativas y por su sorprendente erudición - Hipias se jactaba de dominar muchos oficios - abandonan el cultivo terapéutico de su alma, y se le agosta hasta el punto de perder la interioridad. El

${ }^{3}$ Cf. Gorgias 526d-527a. El subrayado es nuestro. 
Yo del sofista carece de «afuera y adentro»; ha devenido un fantasma, pura apariencia. Son petulantes, soberbios y engreídos porque no se conocen a sí mismos. La historia que cuentan de sí mismos destila arrogancia, porque desconocen sus limitaciones. Sócrates es sabio porque ha sido capaz de reconocer su ignorancia y eso lo coloca, paradójicamente, por encima de sus adversarios.

Los héroes homéricos viven para el honor y eso es, ciertamente, privilegiar la apariencia. Pero Héctor, Áyax, Aquiles se esfuerzan por emprender grandes acciones, porque creen que la posteridad sólo alabará la excelencia del carácter (valentía, lealtad, amistad, justicia). Viven para el escenario, sin embargo, su vida se identifica con su actuación. No falsifican acciones para que les aplauda el público, sino que cultivan las excelencias humanas para pervivir en la memoria de los hombres libres. Por ello, los diálogos socráticos, aquellos donde Platón no imposta su voz valiéndose de su maestro, indagan la definición de virtud (areté), ya sea la hombría en el caso del Laques, la justicia en República I, o la piedad en el Eutifrón. La preocupación de Sócrates es ayudar a los jóvenes a vivir auténticamente según el modelo heroico y la falsa sabiduría de los sofistas es un obstáculo para ello. Esos pseudo-terapeutas del alma no pueden enseñar la virtud, porque ni siquiera saben que no la conocen. Los sofistas son los maestros de la superficialidad; anulan el desdoblamiento del Yo, porque pretenden haberse conocido del todo a sí mismos.

El único camino para escapar de esta autosuficiencia es la ironía. Se trata de un método doloroso, un método que consiste en dar por verdadera la aparente sabiduría del adversario y, asumiendo esa supuesta ciencia, hacerle caer en la cuenta su propia ignorancia. Al autosuficiente no se le puede decir: «Eres ignorante». Su soberbia lo ciega. La estrategia de Sócrates consiste en dar por sentada esa sabiduría y mostrarle poco a poco que se trata de una apariencia, debajo de la cual no hay nada sólido o, mejor dicho, no hay nada. El uso de esta dura estrategia contra sus jueces le costó a Sócrates la pena capital.

La ironía - pariente cercana de la burla - se convertirá en un ingrediente esencial de ciertos tipos de relatos autobiográficos. La caricatura que uno hace de sí mismo se relaciona con el gesto iró- 
nico que nos permite no tomar tan en serio ni a los demás ni a uno mismo (la perspectiva de la muerte ironiza todas las acciones humanas). Sócrates descubre en la ironía una herramienta para distanciarnos de nosotros mismos, para abatir el hechizo de la Primera persona («Yo creo», «Yo pienso»), un poder del cual difícilmente podemos escapar.

El encantamiento de la Primera persona es más fuerte cuando el sujeto es tácito, es decir, cuando el «Yo pienso que soy virtuoso» se convierte en «Soy virtuoso». En el «Yo pienso que soy...» se ha filtrado ya la reflexión y, por tanto, el autodistanciamiento. En el caso del sujeto tácito impera el convencimiento de la objetividad. Cuando el sofista afirma «Soy sabio» no resulta fácil de sacarlo del error, pues la certeza tiñe su error con el color de la verdad. «Conócete a ti mismo» quiere decir: taladra la comodidad y certeza de la primera persona, descubre quién eres en realidad, sacude la imagen que tú y los demás han construido sobre tu persona.

En cierto sentido, Sócrates, sin escribir ni una línea, puede catalogarse como el padre de la autobiografía profunda, de la exploración del yo. Esta distinción entre autobiografías profundas y autobiografías superficiales se finca en el desdoblamiento del mundo y del yo en dos esferas: la de la realidad y la de la apariencia. La sinceridad es la cualidad de las primeras, en ellas el escritor pretende describirse sin misericordia, sin concesiones ni paliativos, se trata de un ejercicio ascético o, cuando menos, de un ejercicio terapéutico. La segunda se origina en la mirada autocomplaciente, el escritor se regocija paseando por su Yo, pues le falta espíritu crítico. Está contento consigo mismo y desde su atalaya omnisciente contempla satisfecho sus hazañas y pensamiento.

Mayéutica e ironía son las dos armas que ofrece Sócrates para encontrarse con uno mismo. Pero lo importante no es el encontrarse, sino el cuidar del alma propia. Sócrates no escribe su vida porque no requiere del texto para emprender «bellas acciones». La excelencia del alma, areté, no va aunada a la escritura, sino al autodistanciamiento para escapar del error. La narración de la propia vida en el socratismo sólo se legitima por su valor terapéutico. El camino hacia la excelencia del alma comienza cuando nos reconocemos tal y como somos, no tal y como nos gustaría ser. La rea- 
lidad, el ontos on, - encantadora reduplicación en griego- es el punto de partida del proceso curativo. La verdad juega un papel decisivo en el cuidado del alma.

El Fedón, un diálogo donde el Sócrates histórico ha cedido su voz al Sócrates platónico, explota esta veta terapéutica. La filosofía, afirma Platón, es catarsis del alma; purificación que se concreta, sobre todo, en la meditación de la muerte. El humano de las apariencias evade el tema de la muerte, pues ese penoso e irremediable hecho le otorga el relieve auténtico a la propia existencia. Frente a la muerte, las cosas son lo que son, la justicia es justicia; la sabiduría, sabiduría; la retórica, palabrería y la sofística, ignorancia. Narrar con verdad la propia vida implica nuestro afán de purificar recuerdos, de limpiarlos de falsedades y, sobre todo, exige la entereza para enfrentarnos a nosotros mismos. Meditar sobre la muerte significa entender el carácter precario de nuestro cuerpo, percatarnos de que el mundo sensible, con sus gozos y sus delicias, es mimesis del otro mundo, el realmente-real. Quien no es capaz de entender este desdoblamiento mentirá, por fuerza, a la hora de hablarnos sobre sí mismo.

Platón pone las bases para un tipo de escrito autobiográfico, los itinerarios de almas, que hallarán en el cristianismo romano un campo fecundo. De acuerdo con la lógica de la catarsis, el cuerpo pasa a la categoría de actor secundario. El Yo es el alma y la carne su cárcel. La autobiografía auténtica no relata la vida carnal, sino la mental. Ni la sexualidad ni otros sentimientos y emociones físicos constituyen el núcleo duro del Yo. Una historia contada desde la perspectiva del Yo carnal vendría a ser, entonces, doblemente engañosa: por estar narrada desde el castillo de la primera persona, y por contar lo que menos importa.

El mito de la caverna del libro IV de la República (otro texto donde Platón usurpa el nombre de Sócrates) admite muchas lecturas, una de las cuales engarza con lo expresado hasta el momento. Los cautivos, aún sin purificar, ignoran que lo que contemplan en la pared de la cueva son las sombras del mundo real, ese mundo fuera del alcance de sus ojos. En tanto no rompan las cadenas no podrán contar con verdad su propia historia. Ellos afirmarán que han vivido, que saben quiénes son y dónde viven, pero en realidad han 
habitado en la penumbra. Quien escapa y se topa con la luz del sol sí que puede hablarnos de él y de los otros. Los cautivos escribirán necesariamente una historia falsa, porque sólo creen en el espacio subterráneo. Lo del espacio no es anecdótico. El desconocimiento del propio Yo se imbrica con el desconocimiento del mundo. El ignorante de su propia historia habita también en un espacio ilusorio, sombras engañosamente luminosas. Desconocernos a nosotros mismos acarrea una alucinación global. Por eso cuesta tanto desprenderse de las cadenas.

La tozudez de los reos llega al punto de asesinar a quien pretende liberarlos. Salir del engaño duele; la liberación es todo menos adulación. En el Gorgias, Platón advierte el éxito de las pseudo-terapias por el impacto de su obsequioso discurso. A diferencia de las terapias auténticas, que curan con la verdad, las pseudos-terapias adormecen al alma y al cuerpo con zalemas cortesanas. Los cautivos prefieren a los aduladores, con los logoi retóricos y sofistas se pueden escribir panegíricos y encomios, no biografías y, mucho menos autobiografías auténticas.

Sócrates y, a su modo Platón, hacen del autoconocimiento la clave para la purificación del alma. Pero lo que ahora me interesa ahora es su diagnóstico sobre la dificultad para alcanzar dicho conocimiento. Después de Sócrates, ningún autor puede arrogarse el poder de revelarse cabalmente a sí mismo en un escrito, pues a las dificultades técnicas del caso, se suman otras más arduas: las dificultades morales. Únicamente quien se da muerte a sí mismo a través de la filosofía, mirará limpia y objetivamente, por encima de sus intereses y su autocomplacencia, el propio yo.

No quisiera, sin embargo, dejar de recalcar un hecho: Sócrates no escribió su biografía ni ninguna obra. En el proceso del autoconocimiento la escritura es superflua e, incluso, peligrosa. La ironía es una estrategia terapéutica cuyo valor reside en hacer caer en la cuenta de la propia ignorancia. La mayéutica - inseparable de la ironía - consiste en sacar las verdades que subyacen en el Yo auténtico, y a las que se puede acceder sólo cuando nos hemos liberado de la autosuficiencia. El relato escrito no añade nada a estas curas del alma. Incluso, en cierto sentido, el relato autobiográfico es peligroso, pues excluye la pulla de la tercera persona (recuérde- 
se que Sócrates comparaba su tarea en Atenas como la del tábano sobre el caballo). El diálogo vivo y no la autobiografía es la manera por excelencia para revelar el propio yo.

\section{RESUMEN}

El objetivo de este artículo es recorrer la prehistoria de la autobiografía en la antigua Grecia, desde los cantos homéricos, el olvido presocrático de la conciencia individual, la máxima socrática y délfica del «Conócete a ti mismo», hasta una relectura del mito de la caverna platónico. El autor argumenta que Sócrates, mediante la mayéutica y la ironía, no precisamente a través de la escritura, es capaz de revelar al auténtico yo.

Palabras clave: Sócrates; autoconocimiento; autobiografía; mayéutica; ironía.

\section{ABSTRACT}

The aim of this paper is to explore the prehistory of autobiography in Ancient Greece: from the Homeric verses, the Presocratic oblivion of personal consciousness, the Socratic maxim «You must know yourself», to a rereading of Platonic Myth of the Cavern. The author argues that Socrates, with maieutics and irony, is capable to reveal the authentic self.

Key words: Socrates; self knowledge; autobiography; maieutics; irony. 